\title{
DA EFETIVAÇÃO DO ENSINO DE LÍNGUA PADRÃO: EM BUSCA DE FONTES ATUAIS
}

\author{
Líbia Mara S. Saraiva (UFMG)
}

\section{Introdução}

O ensino de língua padrão escrita, atualmente, tem sido sujeitado a inúmeros questionamentos, em diversos aspectos, tanto sobre como estabelecê-lo, tendo em vista as incoerentes prescrições dos compêndios gramaticais — considerados por muitos como representantes daquilo que é padrão na Língua Portuguesa —, quanto acerca dos exemplos de que se valem esses compêndios para firmarem suas regras.

Após um breve levantamento, notou-se que vários são os elementos que geram polêmicas, no processo de ensino, e até mesmo no ato de redigir textos formais. Mas, como este trabalho se trata apenas de uma pequena parte de uma pesquisa maior, optou-se por analisar, precisamente, o emprego dos pronomes demonstrativos este/esse, esta/essa, isto/isso e a voz passiva sintética.

Movido pela preocupação de como se efetivar esse ensino, e, especialmente, de quais textos utilizar para o mesmo, ou em quais exemplos se pautar, o presente trabalho visa, por meio de uma verificação ainda a curto prazo, mas que pode ser tomada, ao menos, como exemplo, sugerir o uso de textos partícipes do domínio jornalístico para a efetivação do ensino de língua padrão. Tal sugestão deve-se, principalmente, ao fato de que esse domínio abriga uma série de gêneros de diferentes tipos (e também registros!) que, notadamente, integram o cotidiano do cidadão brasileiro.

Este artigo está organizado da seguinte maneira: na seção1, será feita uma comparação sucinta entre a norma padrão e a gramática tradicional, assim como entre o estatuto da linguagem escrita e o da linguagem falada. Na seção 2, descrevo de que maneira a pesquisa foi realizada. Na seção 3, trato da análise, de fato, 
considerando-se as discussões teóricas e práticas referentes aos elementos pesquisados. $\mathrm{Na}$ seção 4, apresento as considerações finais.

\section{Norma padrão $\mathrm{X}$ gramática tradicional e o continuum fala e escrita}

Por um longo período de tempo, acreditou-se que o ensino de língua padrão só se fazia realizável por meio das Gramáticas Tradicionais, de onde eram retirados os exemplos sem qualquer alteração, a fim de que fossem memorizados e praticados sem o direito a discussões e a modificações. Hoje, após muito se ter discutido acerca dos compêndios gramaticais, tornou-se evidente o fato de que os exemplos neles contidos não condizem com a realidade da língua padrão, uma vez que se valem de textos literários, os quais — por seu caráter essencialmente estético — não atendem às características do que deve ser estabelecido como padrão para a sociedade; nas palavras de Rocha (2002, p. 59-60):

Se a língua literária se caracteriza pela ruptura, pela inovação e pela rebeldia, conclui-se que ela não pode servir de modelo para a chamada língua padrão, que é essencialmente conservadora. (...) Também não faz sentido eleger a língua literária dos séculos anteriores como modelo da língua padrão atual, como fazem as gramáticas tradicionais.

Isso porque, entende-se, aqui, como padrão, aquilo que serve de modelo em determinado(s) tipo(s) de situação(ões) (LUFT, 1991). No caso da língua portuguesa escrita, o padrão está relacionado à variedade lingüística utilizada por pessoas escolarizadas e é facilmente compreensível por toda a sociedade.

Ora, se a sociedade brasileira atual necessita de um padrão de escrita formal - como todas as demais sociedades civilizadas —, certamente não será nos compêndios gramaticais que ela o encontrará, haja vista que, como já foi dito, por se servirem de exemplos arcaicos e artisticamente contrários aos usos contemporâneos, as gramáticas tradicionais não mais possuem a credibilidade dos usuários da língua, o que traz à tona a necessidade premente de uma fonte real (e atualizada!) para a uniformização da escrita. 
Sena (1986), valendo-se, também, da postura de Perini (1985) quanto à necessidade de uma gramática atual, já defendia o fato de que existe um padrão de língua escrita que pode ser encontrado em textos da imprensa (mais precisamente em "periódicos de maior importância"), pois que são produzidos por pessoas escolarizadas e por isso refletem a linguagem culta uniforme, a saber:

Temos, pois, uma língua escrita uniforme (para as ciências, para a imprensa e para os documentos oficiais) de que se servem habitualmente os brasileiros de bom nível de instrução, na qualidade de leitores e, em menor escala, como produtores de textos. (SENA, 1986, p. 91).

Para Sena (1986), esse padrão de língua escrita em pouco se difere das normas tradicionais, uma vez que para a escrita devem ser observadas regras um tanto dessemelhantes das que caracterizam a fala, como também assevera Rocha (1999, p. 122,129):

(...) o estatuto da linguagem escrita é diferente do estatuto da linguagem falada. Embora se trate da mesma língua, ninguém pode negar que as duas modalidades apresentam características diferentes. (...) A língua padrão caracteriza-se pela tradição e pela obediência aos cânones gramaticais... [Nela] há a observância das normas gramaticais e o predomínio da função informativa.

Nesse sentido, tanto para Marcuschi (2003) como para Decat (2002, apud MARQUES, 2005), as modalidades escrita e falada diferenciam-se de acordo com seus usos em contextos determinados, uma vez que derivam de práticas sociais, em condições específicas de produção. Por isso, faz-se necessário

(...) considerar as diferenças entre situação de fala e situação de escrita, ou seja, entre as condições de producão textual nos diferentes contextos de uso, ou nas diferentes práticas sociais (a família, o dia-a-dia, o telefonema, o escritório, a escola, o trabalho, etc, etc.) (DECAT, 2002, p. 92).

Isso porque, para esta mesma autora, “...as diferenças de uso vão levar a diferenças textuais".

É exatamente nessa mesma perspectiva que Lemle (1984) propõe, para o sucesso do "alfabetizador", a precisão de “...idéías claras quanto à relação entre 
língua falada e língua escrita, [uma vez que] a língua escrita, na nossa sociedade complexa, é uma entidade autônoma, diferente da língua falada por quem quer que seja." (p. 81).

Também Risso (s.d), ao discutir as relações entre língua falada e língua escrita, afirma que, (LE para Língua Escrita e LF para Língua Falada)

regidas por um mesmo sistema léxico-gramatical, LE e LF organizam diferentemente os seus padrões de construção, sempre a partir de especificidades de processamento, transmissão e recepção ajustadas a diferentes situações comunicativas e a diferentes condições de produção (p. 62).

Ou seja, consoante esta autora, há, tanto para a língua escrita, assim como para a língua falada, perfis de organização que as estilizam de acordo com o evento e/ou objetivo comunicativo a que se propõem, haja vista que, nas duas modalidades, faz-se possível

observar a manifestação da variação formal/informal...e que, portanto, podemos ter uma LF formal (por exemplo, em certas entrevistas e conferências) e uma LE informal (em cartas pessoais, bilhetes, em certas seções de revistas que procuram um toque de informalidade no "diálogo" com o leitor). (RISSO, s.d., p. $59)$.

Conforme Gnerre (1985), o valor das produções lingüísticas depende da adequação dessas ao contexto em que são produzidas e vale considerar, aí, as influências que ocorreram na história da língua e que foram determinantes para as diferenciações lingüísticas. Tais determinantes também promoveram uma transformação da variedade lingǘstica em registro escrito e desse à tradição gramatical, por isso é possível afirmar que a escrita foi e sempre será diferente da fala.

Portanto, para um trabalho viável no que respeita ao funcionamento da língua escrita, deve ser considerado aquilo que está realmente em uso nos registros formais, para o que ROCHA (1999) sugere textos da mídia impressa contemporânea: "textos da linguagem burocrática, administrativa, técnica, 
científica, etc." , justamente pelo fato de esses textos serem redigidos na modalidade padrão e serem de uso freqüente no dia-a-dia da sociedade em geral.

Importa mencionar que tanto Sena (1986) como Rocha (1999, 2002) acreditam ser a língua escrita o modelo para se tomar como padrão, já que, como têm demonstrado em suas pesquisas, a mesma quase não sofre influências da língua falada, o que mantém "seu caráter de permanência e seu menor grau de variabilidade, sendo bastante una em todo o país”. (SENA, 1986, p. 17).

Isso não significa dizer que não se crê na evolução da língua escrita. Ao contrário, acredita-se que toda língua, de uma forma ou de outra, passa por estágios de evolução. Ocorre que, como afirma Bagno (2000), "verba volant, scripta manent", ou seja, ainda que sofra modificações ao longo do tempo, a escrita, por evoluir de forma mais lenta, possui realizações mais fixas do que a fala.

Todavia, esse mesmo autor (BAGNO, 2004), ainda que considere a diferença de evolução entre fala e escrita, não acredita na possível existência da unidade lingüística, o que ele caracteriza como um “mito": "É preciso, portanto, que a escola e todas as demais instituições voltadas para a educação e a cultura abandonem esse mito da "unidade" do português no Brasil." (p. 18) —, talvez por não ter explícita, em suas obras, a devida separação entre língua falada e língua escrita.

Esse parece ser um dos grandes equívocos que têm cometido diversos autores, ao tratarem do estudo da Língua Portuguesa, pois se não se leva em consideração a distinção entre fala e escrita, qualquer sugestão de padronização da língua se torna falha — uma vez que para o texto escrito há padrões diferentes dos que existem para a língua falada culta, que também possui seu padrão, porém com um maior grau de variação.

Nesse sentido, muitos autores defendem o fato de que se deve caracterizar a escrita conforme as influências da fala, que a devem constituir. Tome-se, como exemplo, a declaração de Possenti (1996, p. 41), quando afirma que “(...) trata-se de 
aceitar que se utilizem também nos textos escritos formas lingüísticas mais informais (...), que em geral consideramos aceitáveis apenas na fala.”

Ora, se se passarem a aceitar na escrita ocorrências da fala, não se fará possível o alcance de nenhuma uniformização, já que ocorrem, a todo o momento, mudanças significativas na fala, que evolui de forma bastante veloz: "verba volant", o que incorreria em constantes modificações nas regras da escrita. Isso, certamente, acarretaria grandes e sérios problemas no que tange ao ensino da Língua Portuguesa, pois, de um momento para o outro (arrisca-se a dizer: talvez de um ano para o outro), professores e alunos deparar-se-iam com tamanhas alterações nas regras, de modo que o que fosse ensinado/aprendido durante um ano exigiria novas discussões/estudos. Tal posicionamento formaria um "círculo vicioso", onde professores não saberiam o que ensinar e aos alunos nada seria acrescentado, além de confusões e inseguranças quanto a sua própria língua.

Sobre isso há, ainda, uma outra afirmação de Bagno (2000, p. 158): “não existe uma "variedade-padrão", o que contribui para intensificar a desordem, principalmente para os que lidam com o ensino. Assim se posiciona esse autor por acreditar que o que se considera padrão de uma língua trata-se de "uma abstração, um ideal" inatingível e, para tratar das variedades - que ele considera através de um continuum —, o mesmo vale-se das acepções "+ cultas" e "- cultas". Nesse caso, ele iguala, então, a norma-padrão às Gramáticas Normativas, como um modelo ‘imaginário perfeito’.

Comunga-se da opinião de Bagno (2000) no que tange às prescrições da gramática, haja vista que, por se pautar na literatura antiga, as gramáticas apresentam, por vezes, exemplos que não condizem com a realidade brasileira esteja essa realidade ligada ao uso escrito e/ou (menos, ainda!) falado. Todavia, no que concerne à questão do ensino, permanece a dúvida (ou, as dúvidas) de como 'oferecer' ao aluno um ensino de língua alicerçado em usos atuais e autênticos neste caso específico, da língua escrita — , com vistas a torná-lo um leitor/escritor proficiente em meio à sociedade presente. 
Compreende-se que é preciso ter em mente a devida clareza de que há, para todas as línguas, variações tanto na escrita como na fala e que a Gramática Tradicional não deve ser vista como "um ideal de língua". Pois bem: o que fazer, então? Seria o caso de dizer aos alunos que, por ser "inatingível", eles jamais chegarão à produção de um texto formal, como os que circulam na mídia impressa contemporânea? Ou seria o caso, também, de dizer a eles que "não se sabe, ainda", como ensinar o estilo de escrita do meio acadêmico, por exemplo?

Certamente, para o professor, a 'desordem' está instaurada e é exatamente nesse conflito que eles se encontram, pois, de posse da leitura desses autores, esses profissionais simplesmente "ficam sem saber" o que fazer, uma vez que deles é exigido o ensino da língua escrita padrão - considerada, aqui, não como o "ideal" fantasioso da língua, tampouco como sinônimo da Gramática Tradicional, mas sim, como uma variedade: aquela que o próprio autor em questão chama de "+ culta". E esse ensino é exigido sem, por vezes, o uso da Gramática Tradicional, o que lhes acrescenta a desorientação.

Diante desse impasse, paira no ar, para muitos professores, e demais profissionais da língua, a dúvida de como ensinar, então, língua padrão aos alunos, e em que se basear nas correções e revisões textuais sem o estudo da gramática tradicional, em que são comuns questionamentos vários, como: "Existe um padrão de escrita para/no Português?", "Onde encontrá-lo?”, "Esse padrão sofre influências diretas da língua falada?", "Se isso ocorre, até que ponto o padrão pode ser considerado realmente padrão?".

Ao que Rocha (2002) responde:

Parece não haver dúvida de que a chamada língua padrão existe. [Logo] a fixação das regras que caracterizam o português padrão deve tomar como base o conjunto dos textos redigidos nessa língua padrão, ou seja, os textos da linguagem burocrática, administrativa, técnica, científica, etc. É importante que se leve em consideração aquilo que é freqüente nesses textos, [pois] caracterizam o que se pode chamar de língua padrão do português contemporâneo e é desses tipos de texto que devem ser extraídas as abonações que 
servirão de base para fixação das regras gramaticais que descreverão a língua culta escrita do português do Brasil. (p. 53, 63 e 67).

Note-se que o autor chama a atenção para "aquilo que é freqüente", isto é, trata-se de considerar que o que caracteriza o padrão de uma língua é precisamente o que lhe parece comum, o que constitui o seu caráter usual, exaustivo. Só se pode concluir, então, se o padrão sugerido para a escrita é ou não influenciado por traços da fala verificando-o, analisando-o, atentamente - o que busca este trabalho.

\section{Uma abordagem alternativa para a caracterização da norma culta escrita: o percurso desta investigação}

Com vistas a examinar - e descrever - o que se apresenta de maneira uniforme na língua culta escrita procedeu-se a uma pesquisa em textos da mídia impressa contemporânea, mais especificamente, em revistas "Época", dos meses de maio e junho do ano de 2005. A escolha desse corpus se deu pelo fato de o mesmo representar uma das publicações de grande circulação, onde se espera que seja empregada uma modalidade lingüística padronizada, que contribua para a caracterização da norma culta escrita neste país.

Devido ao grande número de fenômenos que compõem a escrita padrão da língua portuguesa e ao período exíguo de tempo/espaço a que esta pesquisa foi submetida, fez-se uma seleção entre os mesmos, em que se optou por investigar dois daqueles que geram controvérsias quanto ao uso na fala e/ou na escrita, ou seja, buscou-se averiguar se esses fenômenos aceitam, na escrita, interferências da fala, ou se são registrados consoante os ditames tradicionais, para o que foram examinados: a) o emprego de este/esse, esta/essa, isto/isso e b) a voz passiva sintética.

Para empreender esta pesquisa, procurou-se observar, portanto, de que maneira esses elementos têm-se apresentado na linguagem culta escrita, isto é, se o que caracteriza a sua freqüência refere-se ou não à norma tradicional. Por isso, não foram pesquisados textos propagandísticos, tampouco as entrevistas, as crônicas, os discursos diretos, etc., por se fazerem mais passíveis a não observância dos padrões 
tradicionais, pois que possuem outros objetivos, que não o meramente informacional. Considerou-se, na pesquisa, apenas a linguagem da revista, como os textos de notícia e reportagem, os editoriais, etc.

Os dados foram coletados à medida que apareceram no texto, conforme a ordem de ocorrência dos mesmos.

Com isso, buscou-se verificar, nas amostras em reais condições de funcionamento, se o que se faz constante nesses textos admite intervenções sintáticas das construções da língua falada: até que ponto esse tipo de texto constitui base para o estabelecimento da língua padrão escrita, a saber.

\section{Uma análise crítica das abordagens tradicionais}

A fim de analisar os fenômenos mencionados, foram apontadas, nesta pesquisa, posições de alguns lingüistas quanto às regras tradicionais, com que se efetuou o cotejo dos resultados alcançados. Revisadas algumas obras que tratam do estudo desses fenômenos, passar-se-á a análise dos mesmos, de acordo com o levantamento real dos dados coletados na investigação.

\subsection{Voz passiva sintética:}

Visto que o estudo da Concordância Verbal tem apresentado sérios problemas tanto de análise como de uso, atentar-se-á, aqui, para o caso das orações em que se encontra a partícula -se como apassivadora da oração em exemplos como abaixo:

(1) Vendem-se carros;

(2) Emprestam-se livros;

(3) Não se podem atribuir a elas os erros que encontramos; etc.

Conforme a gramática tradicional, existem três vozes verbais: a voz ativa, a reflexiva e a passiva (que se divide em sintética e analítica). E, esta última, é, dentre as vozes verbais, a que vem sendo alvo das mais diversas "confusões" concernente ao seu estudo e análise.

Segundo os ditames tradicionais, a voz passiva ocorre quando o sujeito é o ser que sofre a ação expressa pelo verbo (o que é contraditório quando comparado 
à classificação tradicional do sujeito enquanto elemento que pratica a ação verbal) e pode ocorrer de duas maneiras: uma delas é a de forma desenvolvida, com um verbo auxiliar mais verbo na forma nominal de particípio, como em "A lata foi aberta pela menina". (a lata -sujeito- sofre a ação de ser aberta pela menina). Essa forma é chamada, pela gramática tradicional, de "voz passiva analítica". A outra maneira de se construir a vOz passiva, conforme a Gramática Tradicional (doravante, GT), seria com o verbo na terceira pessoa seguido do pronome -se, o qual, quando da voz passiva, será denominado pronome apassivador, como nos exemplos: "Vendem-se roupas"; "Compra-se metal", o que permite uma pequena observação: ora, se na voz passiva o sujeito sofre a ação verbal, onde estaria o sujeito em tais orações?

Conforme já explicitado, na voz passiva o sujeito é o termo que sofre a ação expressa pelo verbo. Assim, em "Comem-se maçãs", tradicionalmente, o termo maçãs deve ser entendido como sujeito, e, estando no plural, o verbo deve concordar com ele, flexionando-se igualmente para o plural. Já em "Lề-se o livro", o termo livro, agora no singular, por ser tradicionalmente entendido como sujeito, é acompanhado pelo verbo em número.

Para justificar os termos maşãs e livro como sujeitos das chamadas orações passivas sintéticas, a GT propõe o contraste entre as vozes passivas. Assim, basta "transformar" a voz passiva sintética em voz passiva analítica: $\rightarrow$ Alugam-se casas $=$ vOz passiva sintética $\rightarrow$ Estas casas são alugadas $=$ voz passiva analítica. Por considerar o termo casas sujeito da oração na voz passiva analítica, a GT dita ser ele também sujeito na voz passiva sintética, justificando, assim, o plural do verbo quando o sintagma nominal estiver no plural.

Desse modo, a GT considera a construção "Aluga-se esta casa" como contenedora da mesma carga semântica que "Esta casa é alugada" (transformou-se a voz passiva sintética em voz passiva analítica), o que Bagno (2001) refuta ao dizer que tal observação se faz um tanto incoerente, em ambas construções, pois que em “Alugam-se estas casas" percebe-se que a ação verbal não é concluída: as casas estão 
passíveis de serem alugadas por alguém; e isso não se repete em "Estas casas são alugadas", por se perceber claramente que a ação verbal é conclusa: as casas já estão alugadas por alguém.

Ainda consoante as análises desse autor, há uma incompatibilidade semântica entre ambas, pois, da leitura do primeiro exemplo (Aluga-se esta casa), infere-se a existência de um sujeito X que não se sabe quem é (Alguém que não conhecemos aluga esta casa), e, no segundo (Esta casa é alugada), atribui-se uma qualidade para a casa: Esta casa é alugada (e não pintada, ou vendida, por exemplo). Nota-se, claramente, que o verbo de "Aluga-se esta casa" se transformou em adjetivo em "Esta casa é alugada", mudando-se a função sintática.

Avançando um pouco nos critérios semânticos, ressalta-se que se alguma pessoa (A) pretende alugar uma casa e pergunta para alguém (B) se esta casa está para ser alugada, o ato de "alugar" vai depender da resposta que (A) obtiver de (B). Se (B) disser, defronte a tal casa: "Aluga-se esta casa", (A) provavelmente entenderá que não há moradores na casa, ou que a casa está vazia, pronta para ser alugada. No entanto, se (B) disser "Esta casa é alugada", (A) poderá entender que já existem moradores na casa, o que o impedirá, então, de alugar a casa que almeja.

Logo, o que se percebe é uma não correspondência semântica entre a chamada vozpassiva sintética e a vozpassiva analitica em Língua Portuguesa, conforme as normas prescritas pela GT. Por esse motivo, Bagno (2001) se refere a essas orações passivas sintéticas, assim intituladas pela GT, como sendo um mito, afirmando que as mesmas simplesmente não existem. Assim, ele as nomeia como pseudopassivas, como ilógicas, sem sentido, considerando como passivas apenas as chamadas analíticas pela GT. Ou seja, as orações formadas comumente pelo verbo ser.

Por meio de diversos exemplos, Bagno (2001) busca comprovar a ilogicidade da doutrina gramatical ao afirmar que o -se funciona como partícula apassivadora, em construções do tipo "Vendem-se fogões", fazendo com que o termo fogões seja classificado como sujeito da oração. Isto é, conforme a GT, na referida frase, o 
verbo deve, então, aparecer no plural, concordando com seu sujeito. O autor critica também, juntamente com Mourão (2001), o fato de a regra da GT pautar-se apenas no critério sintático e ser "comprovada" através de meros testes, desconsiderando os aspectos pragmáticos e semânticos do fenômeno.

Contrariamente à GT, Bagno (2001), por meio de seus exemplos, explica que o fato de muitos falantes manterem o verbo da referida oração no singular se deve à interpretação da partícula -se como indicadora de indeterminação do sujeito. Para a GT, ler-se-ia a construção "Alugam-se mesas" como alugam - o verbo, se - a partícula apassivadora e mesas - sujeito da oração. Entretanto, para Bagno (2001), essa classificação representa uma incompatibilidade tamanha, pois se se considerar o aspecto semântico, certamente se constatará que o referido verbo (e o(s) dos demais exemplos) só pode ser praticado por um sujeito, visto que somente seres humanos são capazes de alugarem mesas, assim como venderem fogões, etc.

Assim, esse autor considera a proposta dos tradicionalistas altamente antipedagógica, alegando que não se deve, de maneira alguma, apresentar aos alunos uma regra baseada em truques e/ou 'decorebas', mas sim, apresentar a natureza científica do fenômeno analisado, considerando-se a realidade dos fatos. Mourão (2001) completa essa alegação ressaltando que há, por parte dos falantes do português, e também escritores consagrados, uma tendência em interpretar o sujeito das sintéticas como indeterminado, o que explicaria o fato de se encontrarem diversos enunciados do tipo "Aluga-se casas; Dá-se aulas de violão; Vendese salgados; Passa-se materiais de construção...”. Isso porque, segundo essa autora, os que assim escrevem, o fazem crendo na indeterminação expressa do sujeito. Isto é, sabe-se que diversos serviços são oferecidos por alguém — que está representado pelo que aqui seria índice de indeterminação -se. E o que a gramática normativa nomeia como sujeito, os autores desses enunciados, conforme afirma Mourão (2001), classificam como objeto, já que alguém, não se sabe quem, vende, aluga alguma coisa. 
A fim de comprovar a inadequação da regra gramatical, como a respeito do termo casas no enunciado "Aluga-se casas", que seria um sujeito e não objeto, como grande parte dos falantes acreditam, Bagno (2001) declara que a prescrição gramatical tem sido desconsiderada em, até mesmo, escritos de requinte.

Torna-se aqui imprescindível pontuar o fato de os autores supracitados, ao se referirem ao estudo da vozpassiva, mais especificamente, ao caso das orações em que encontramos a partícula -se como apassivadora, elemento aqui pesquisado, ousarem afirmar que a utilização - falada e escrita — da mesma não tem seguido os moldes tradicionais, ao contrário, partilhando da opinião de Mourão (2001), Bagno (2004) assevera que

muitas pesquisas científicas, baseadas em coleta de dados da língua real, em levantamentos estatísticos rigorosos e em teorias lingüísticas consistentes, mostram que a imensa maioria dos brasileiros - de todas as classes sociais, cultos ou não, na língua falada e na língua escrita - usam verbos no singular nos enunciados em que aparece o se com um verbo transitivo e um substantivo no plural: Vende-se casas, Aluga-se salas, Joga-se búzios, Avia-se receitas..." (p. 98, Grifos meus).

Vale ressaltar que se compartilha da postura desses autores no tocante às ocorrências na língua falada e na língua escrita informal, haja vista que nelas notase, comumente, uma não observância das regras tradicionais, quando da utilização da voz, passiva sintética, em que o verbo fica no singular, mesmo estando o sujeito passivo no plural.

Entretanto, por meio desta pesquisa, verificou-se que o mesmo não ocorre na linguagem escrita culta, pois as 79 ocorrências encontradas aparecem de acordo com a norma tradicional, isto é, tanto as estruturas com um núcleo verbal como as constituídas com dois verbos seguem os ditames tradicionais, conforme tabelas abaixo: 
TABELA 1 - Voz passiva sintética com 1 verbo

\begin{tabular}{|c|c|c|c|c|c|}
\hline \multicolumn{2}{|c|}{ GT Sim } & \multicolumn{2}{c|}{ GT Não } & \multicolumn{2}{c|}{ TOTAL } \\
\hline $\mathrm{N}^{\mathrm{o}}$ & $\%$ & $\mathrm{~N}^{\mathrm{o}}$ & $\%$ & $\mathrm{~N}^{\circ}$ & $\%$ \\
\hline 72 & 100 & 00 & 00 & 72 & 100 \\
\hline
\end{tabular}

TABELA 2 - Voz passiva sintética com 2 verbos

\begin{tabular}{|c|c|c|c|c|c|}
\hline \multicolumn{2}{|c|}{ GT Sim } & \multicolumn{2}{c|}{ GT Não } & \multicolumn{2}{c|}{ TOTAL } \\
\hline $\mathrm{N}^{\mathrm{o}}$ & $\%$ & $\mathrm{~N}^{\mathrm{o}}$ & $\%$ & $\mathrm{~N}^{\mathrm{o}}$ & $\%$ \\
\hline 07 & 100 & 00 & 00 & 07 & 100 \\
\hline
\end{tabular}

Notável é que tais estruturas aparecem em pequena quantidade, pois tem-se observado uma maior preferência por estruturas consideradas passivas analíticas talvez pela complexidade que possuem as de formas sintéticas. Quanto às passivas sintéticas com mais de um núcleo verbal, o número torna-se ainda menor (apenas 07 ocorrências), do que podemos deduzir que tais estruturas têm-se tornado cada vez mais raras na língua escrita, pois a quantidade dessas equivale a apenas $8,86 \%$ do total:

TABELA 3 - Voz passiva sintética

\begin{tabular}{|c|c|c|c|c|c|c|c|c|c|}
\hline \multicolumn{2}{|c|}{ GT Sim } & \multicolumn{2}{c|}{ GT Não } & \multicolumn{2}{c|}{ GT Sim } & \multicolumn{2}{c|}{ GT Não } & \multicolumn{2}{c|}{ TOTAL } \\
1 verbo & \multicolumn{2}{c|}{1 verbo } & \multicolumn{2}{c|}{2 verbos } & \multicolumn{2}{c|}{2 verbos } & \multicolumn{2}{c|}{} \\
\hline $\mathrm{N}^{\mathbf{o}}$ & $\%$ & $\mathrm{~N}^{\mathrm{o}}$ & $\%$ & $\mathrm{~N}^{\mathbf{0}}$ & $\%$ & $\mathrm{~N}^{\mathbf{0}}$ & $\%$ & $\mathrm{~N}^{\mathbf{0}}$ & $\%$ \\
\hline 72 & 91,14 & 00 & 00 & 7 & 8,86 & 00 & 00 & 79 & 100 \\
\hline
\end{tabular}

Isso nos permite concluir que, mesmo em número bastante reduzido, as construções passivas sintéticas, quando no plural, mantêm os verbos também no plural, diferente do que afirmam os lingüistas citados, como em: "Buscam-se a simetria e a beleza" (Revista "Época", no 370, p. 66-c). E, por mais que sejam raras as construções, principalmente as das passivas sintéticas com dois verbos, não se deixa 
de fazer a concordância com o plural, como estabelecem as GT's: "Não se podem atribuir ao Governo as faltas que desvendamos".

Portanto, por mais "ilógicas" que possam parecer as estruturas passivas sintéticas, tais investigações vão de encontro às afirmações dos lingüistas, em especial, às do lingüista Bagno (2004), quando diz que as "orações passivas sintéticas (...) simplesmente não existem” (p. 98). Será que os periódicos atuais se valem daquilo que "não existe"? Será que o que podemos ler nas revistas que circulam cotidianamente em meio a nossa sociedade é apenas uma 'visão alucinatória do desejo de purismo’?

Certo é que, por mais que as construções passivas sintéticas com dois verbos estejam caminhando para uma possível extinção - o que, certamente, não as transforma em um desejo! -, aquilo que se vê nas revistas atuais é o corrente nos usos cultos da língua escrita, é o que tem sido escrito/lido. Trata-se, então, daquilo que constitui a norma, por seu caráter constante, nos moldes tradicionais, o que também foi constatado por Lima (2003), em sua pesquisa acerca desse fenômeno:

Na pesquisa feita com textos técnicos, científicos e jornalísticos, ficamos diante do seguinte quadro: enquanto a passiva sintética com um único verbo é relativamente comum, observa-se um uso bastante restrito da construção com dois verbos (...) Podemos afirmar que a maioria dos textos formais coincide com a norma fixada pela gramática clássica. (p. 188-189).

\subsection{Pronomes demonstrativos:}

Outro fenômeno que tem apresentado variações com relação à linguagem oral é o emprego dos pronomes demonstrativos este/esse e suas flexões, para o que a gramática tradicional estabelece três disposições: referentes ao espaço, à noção de tempo e aos elementos do discurso.

Na primeira delas, no uso de demonstrativos referentes ao espaço, há que se fazer sua aplicação com -t- para os seres que pertencem ou estão próximos da $1^{a}$ pessoa, como em "Nesta revista", e com -ss- aos que pertencem ou estão próximos da $2^{\mathrm{a}}$ 
pessoa: "Essa é a sua face", do que contextualizado se tem o seguinte exemplo, colhido na Revista Época, ano 2005, de número 366:

Exemplo de pronome demonstrativo referente ao espaço com -ss-:

a) “...como o jequitibá, e outras genuínas, da Floresta Amazônica, como a maçaranduba. Há representantes da flora que ocorrem apenas nessa região, como a arruda e o arapati." (Grifo meu).

Logo, o pronome este (e suas flexões) se refere ao lugar donde se escreve e o esse para onde se escreve.

A segunda disposição diz respeito à noção de tempo, para o que a norma dita a utilização do pronome este (e flexões) para se referir ao momento em que se fala, como em “...O Aprendiz de Feiticeiro e Espelho Mágico, prometidos para este ano”, e do pronome esse (mais flexões) quando se remete a tempo passado, a seguir, em um dos exemplos colhidos:

Exemplo de pronome demonstrativo referente à noção de tempo com -ss-:

b) "Nunes comandou a Bombril entre 2003 e 2004. A atual administração, do economista José Edson Bacellar Júnior, mandou passar um pente-fino na empresa para detectar problemas anteriores. Um relatório de investigação elaborado pela Wolfe Associates descobriu fortes indícios de irregularidades nas exportações da companhia durante esse período." (Revista Época, 2005, n 366, p. 42, grifo meu).

Vale dizer que isso irá variar, gradualmente, a depender do contexto de/em que se fala.

Já a terceira disposição alude às nossas próprias palavras, considerando-se os elementos do discurso: anáfora e catáfora, para a qual algumas gramáticas defendem o emprego de este (com flexões), enquanto outras prescrevem o uso de esse, a saber:

Exemplo de pronomes demonstrativos referentes às nossas próprias palavras com -ss- e -t-: 
c) "Desta vez, o ineditismo é a desenvoltura de um burocrata ao negociar em nome de um partido. Esse fato pode ser explicado...”;

d) "O PT viu-se obrigado a lotear os cargos públicos com aliados de última hora. Esse tipo de combinação..."

e

e) "Os casos de corrupção revelados na semana passada foram praticados por políticos e burocratas, mas em nada diferem do pagamento de propina a um guarda ou a um fiscal pelo motorista ou pelo comerciante que querem se livrar da multa. Talvez porque esses pequenos delitos raramente sejam mostrados nos jornais e na TV" (Grifo meu, Revista Época, 2005 no 366, p. 42).

Como pode ser observado nos exemplos acima (de c a e), há tanto o uso do pronome com -ss- quanto com -t-. Nessa perspectiva, vale pontuar o fato de as próprias gramáticas assumirem o caráter embaraço do emprego desses pronomes demonstrativos referentes às nossas próprias palavras e também considerarem as construções já fixadas, como "isto é", "por isso, nem por isso, além disso" e "isto de”, que também podem ser empregados em casos como os citados de c a e.

Desse modo, constatou-se, nesta pesquisa, que todos os casos encontrados — tanto com -ss- como com -t- — estão em conformidade com a norma canônica, em que se observa, também, uma grande preferência do uso de pronomes demonstrativos com -ss- $(78,16 \%)$, o que não tem impedido uma considerável utilização dos pronomes com -t-, principalmente para se referir ao tempo, como em "O grupo é acusado de ter desviado, só neste ano... "; comprovam as tabelas abaixo:

TABELA 4 - Pronome demonstrativo esse (e flexões)

\begin{tabular}{|c|c|c|c|c|c|}
\hline \multicolumn{2}{|c|}{ GT Sim } & \multicolumn{2}{c|}{ GT Não } & \multicolumn{2}{c|}{ TOTAL } \\
\hline $\mathrm{N}^{\mathrm{o}}$ & $\%$ & $\mathrm{~N}^{\mathrm{o}}$ & $\%$ & $\mathrm{~N}^{\circ}$ & $\%$ \\
\hline 365 & 100 & 00 & 00 & 365 & 100 \\
\hline
\end{tabular}


TABELA 5 - Pronome demonstrativo este (e flexões)

\begin{tabular}{|c|c|c|c|c|c|}
\hline \multicolumn{2}{|c|}{ GT Sim } & \multicolumn{2}{c|}{ GT Não } & \multicolumn{2}{c|}{ TOTAL } \\
\hline $\mathrm{N}^{\mathrm{o}}$ & $\%$ & $\mathrm{~N}^{\circ}$ & $\%$ & $\mathrm{~N}^{\circ}$ & $\%$ \\
\hline 102 & 100 & 00 & 00 & 102 & 100 \\
\hline
\end{tabular}

TABELA 6 - Pronomes demonstrativos

\begin{tabular}{|c|c|c|c|c|c|c|c|c|c|}
\hline \multicolumn{2}{|c|}{ GT Sim } & \multicolumn{2}{c|}{ GT Não } & \multicolumn{2}{c|}{ GT Sim } & \multicolumn{2}{c|}{ GT Não } & \multicolumn{2}{c|}{ TOTAL } \\
com -ss- & \multicolumn{2}{c|}{ com -ss- } & \multicolumn{2}{c|}{ Com -t- } & \multicolumn{2}{c|}{ com -t- } & \multicolumn{2}{c|}{} \\
\hline $\mathrm{N}^{\mathrm{o}}$ & $\%$ & $\mathrm{~N}^{\mathrm{o}}$ & $\%$ & $\mathrm{~N}^{\mathbf{0}}$ & $\%$ & $\mathrm{~N}^{\mathbf{o}}$ & $\%$ & $\mathrm{~N}^{\mathbf{o}}$ & $\%$ \\
\hline 365 & 78,16 & 00 & 00 & 102 & 21,84 & 00 & 00 & 467 & 100 \\
\hline
\end{tabular}

Conforme se pode notar, mesmo inseridos em imposições um tanto contraditórias, os pronomes demonstrativos têm sido bastante utilizados. $\mathrm{Na}$ verdade, em poucas páginas lidas de um periódico, é possível encontrar vários exemplos desse tipo de pronome, ou seja, trata-se de um elemento usual, tanto na fala como na escrita. $\mathrm{O}$ seu registro escrito formal se faz em consonância com a norma tradicional, sem interferência da fala, nesse sentido, o que é corroborado por Bechara (2003) quando afirma que o ensino do uso tripartido dos demonstrativos este/esse/aquele terá de observar a sintaxe desses pronomes na língua escrita formal.

\section{Considerações finais}

Por acreditar que cabe à escola a faculdade de possibilitar ao aluno o conhecimento e a capacidade de lidar com as diversas manifestações lingüísticas, a fim de amplificar seus saberes acerca de sua língua, objetivou-se, com a investigação efetuada, uma contribuição a mais para a caracterização da norma culta escrita atual, em prol do ensino da Língua Portuguesa, pois, como afirma Ramos (1997), é realmente necessário que o aluno tenha, além do seu próprio dialeto, 
acesso à linguagem de pessoas cultas, quer pela mídia quer por outros meios, a fim de que o professor deixe de ser o único porta-voz dessa variedade lingüística, como também o único destinatário dos textos produzidos pelos alunos.

Entende-se que para o estudo da escrita padrão deve ser levado em consideração o uso de textos de acordo com a situação em que foram produzidos. $\mathrm{Na}$ crença de que é "o uso que legitima a norma", propôs-se, aqui, verificar justamente o uso de determinados aspectos da língua, no que tange a sua freqüência em uma situação também determinada, sem desconsiderar a complexidade dos termos que definem a modalidade e o registro nessa situação, bem como a relevância e o papel que cada um desempenha nos mais diversos usos que deles se fazem. O interesse maior residiu, aqui, em uma averiguação de qual uso tem constituído a norma padrão, com relação aos pronomes demonstrativos e à voz passiva, com vistas a contribuir para uma possível caracterização do registro considerado formal em favor de um ensino/aprendizado que se paute em pesquisas atuais e empíricas desses itens na nossa língua portuguesa, uma vez que

A norma lingüística é uma realidade que se constata através de pesquisas, e estas hoje se baseiam, como já vimos, no critério de freqüência. O que é freqüente no uso de uma variedade da língua é que constitui a norma. [Chega-se] a isso pela observação, análise e interpretação dos fatos. (SENA, 1986, p. 75).

Pôde-se verificar que há, de fato, certa regularidade na escrita da imprensa contemporânea, o que a torna útil ao estudo da escrita padrão, de maneira proveitosa; conforme apregoa Possenti (1996, p. 41):

Haveria certamente muitas vantagens no ensino de português se a escola propusesse como padrão ideal de língua a ser atingido pelos alunos a escrita dos jornais ou dos textos científicos, ao invés de ter como modelo a literatura antiga.

No início deste trabalho foram levantadas questões justamente acerca desse ensino, sobre como efetuá-lo e em que baseá-lo, sobre o que, após a análise atenta do material utilizado como corpus desta investigação, se constatou que os dois elementos pesquisados coincidem, em sua totalidade, com a norma tradicional, o 
que permite tomá-los como integrantes daquilo que se tem como modelo padrão; ilustram os seguintes gráficos:

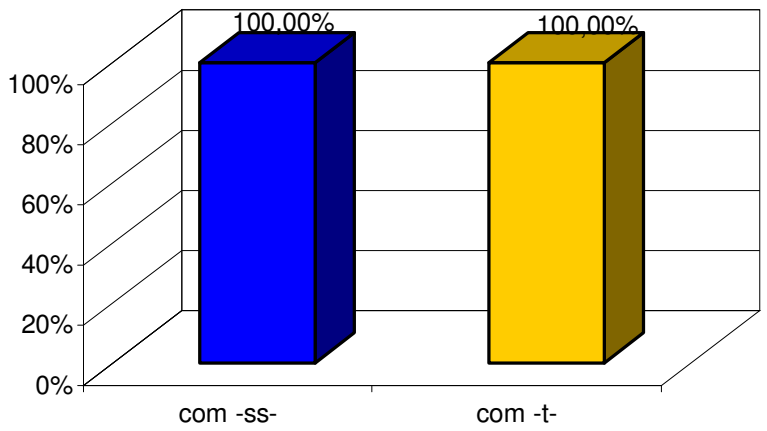

Gráfico 1: Pronomes demonstrativos, conforme a G.T.

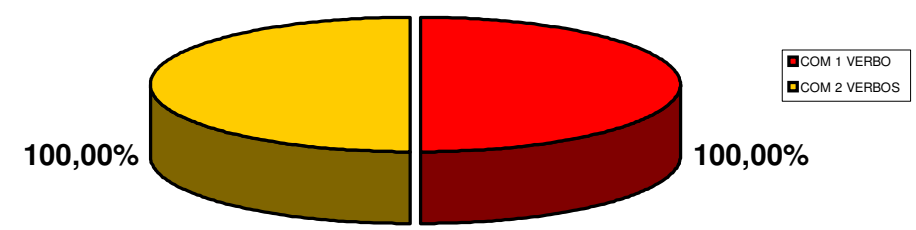

Gráfico 2: Voz passiva sintética, conforme a G.T.

Uma vez que o problema maior do ensino da gramática tradicional tem sido - além das teorias um tanto ambíguas — o uso do texto literário como base para seus pressupostos, comprovou-se, com este trabalho, que os textos da imprensa contemporânea constituem material altamente recomendável para o ensino da norma culta. Haja vista que é na mídia “impressa de maior importância” que se encontram elementos freqüentemente padronizados, pois que constantes e formais, são utilizados por pessoas consideradas cultas.

Ao se apoiar nesse tipo de texto, certamente o professor poderá contar com exemplos reais e verdadeiramente atualizados (ao contrário das "Novíssimas Gramáticas”, que de novo nada trazem!), oferecendo assim, ao aluno, a possibilidade de lidar com o que é corrente e canonizado em sua língua. Assim, terá o professor a 
oportunidade de atingir o veio do ensino de Língua Portuguesa: a formação de leitores e produtores críticos e competentes, realmente capazes de manejar a língua, principalmente o registro escrito formal, o que, consoante Rocha (2002), deve constituir o ensino de língua padrão.

Inegável é o fato de que a língua sofre variações, de uma forma ou de outra, todavia, "nem toda variação constitui mudança", conforme exemplificam os gráficos:

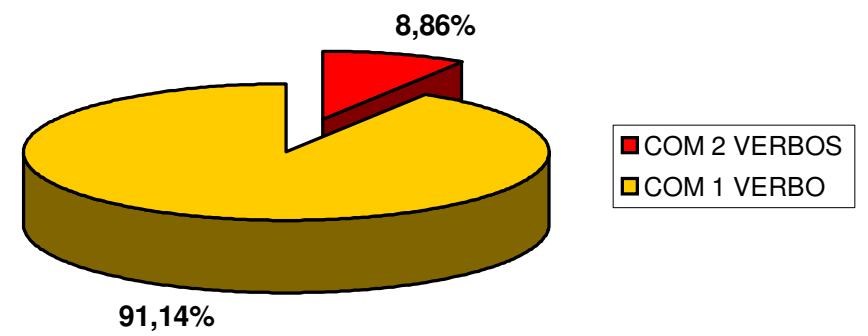

\section{Gráfico 3: Voz passiva sintética:}

Note-se que aí a variação diz respeito, apenas, à opção do usuário de se valer mais de uma forma do que de outra, e não a interferências da língua falada no registro escrito, como pregam alguns lingüistas.

Da mesma forma ocorre com os pronomes demonstrativos, os quais, como se podem ver, têm seu uso variado, conforme escolhas feitas pelo escritor, de acordo, também, com o contexto em que ocorrem.

Ao que tudo indica, há, realmente, alguns itens que necessitam de serem revistos, conforme a baixa freqüência de seu uso e /ou ambigüidade que trazem.

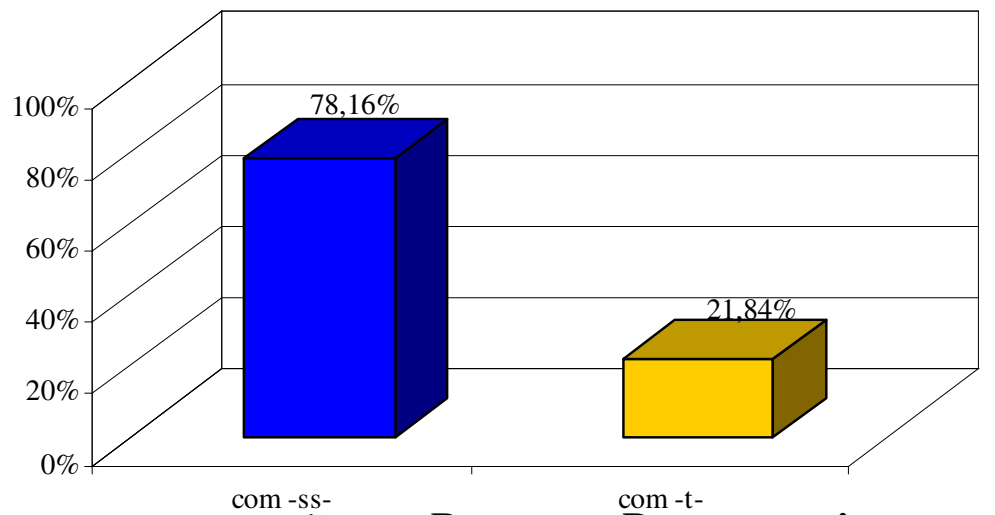

Gráfico 4: Pronomes Demonstrativos 
Entretanto, não se trata da inexistência de uma norma culta, como afirma Dillinger (1995), dentre outros: “(...) é que não faz sentido algum: ninguém sabe explicar por que exatamente estudar uma variante da língua seria melhor, nem por que esta variante específica da língua em vez de outra” (DILLINGER, 1995, p. 39). Tratase, sim, de uma reformulação do ensino de língua, concernente ao corpus utilizado para estabelecer o que pode ser tido como padrão, uma vez que, em diversos momentos deste trabalho, pôde-se demonstrar o contrário do que declara Dillinger (1995): que existe uma norma considerada culta e que ela deve ser ensinada aos alunos, justamente por habitar textos do cotidiano com os quais o educando precisa aprender a conviver — dever, inclusive, de qualquer professor de português.

Por tudo isso, acredita-se, assim, que, o professor, ao buscar a linguagem da imprensa contemporânea para ensinar a norma padrão, deve fazê-lo como um pesquisador, atento e crítico, para que isso, dessa mesma forma, atinja o aluno, pois

o sistema lingüístico do Português, como entidade social que é, deve, pois, ser objeto de um trabalho persistente de sistematização objetiva, coerente e uniforme, alicerçado numa atitude científica de análise dos fatos gramaticais, sem o qual o ensino da nossa gramática continuará sendo deficiente e improdutivo. (HAUY, 1994, p. 4).

Conclui-se, desse modo, que, como postula Rocha (1999, 2002), a linguagem dos periódicos — jornais e revistas — , ainda que aceitem inovações lexicais, vale-se da sintaxe prescrita pela GT, isto é, da norma padrão, o que permite afirmar que tais periódicos constituem, verdadeiramente, material de ensino da norma culta, visto que, outrossim, são textos que circulam na sociedade, e possuem funções reais dentro da mesma, em que se fixa seu formato.

\section{Referências Bibliográficas}

ANDRÉ, Hildebrando A. de. Gramática ilustrada. 4.ed. São Paulo: Moderna, 1990.

BAGNO, Marcos. A língua de Eulália: novela sociolingüística. 6.ed. São Paulo: Contexto, 2000. 
Português on Brasileiro? - um convite à pesquisa. Rio de Janeiro: Moderna, 2001. Cap. 6: Em que se vai trocando as pernas; as orações pseudopassivas. p.123-137.

2004.

. Preconceito lingüístico: o que é, como se faz. 34.ed. São Paulo: Loyola,

BECHARA, Evanildo. Moderna Gramática Portuguesa. 37.ed. Rio de Janeiro: Lucerna, 2003.

CEGALLA, Domingos Paschoal. Novissima Gramática da Lingua Portuguesa (com numerosos exercícios). 45.ed. São Paulo: Companhia Editora Nacional, 2002.

CUNHA, Celso Ferreira da. Gramática da língua portuguesa. 2.ed. Rio de Janeiro: FENAME, 1975.

DECAT, Maria Beatriz do Nascimento. Fala, escrita e gramática. Revista de Estudos da Linguagem, Belo Horizonte, v.10, n. 2, p.83-105, jul./dez. 2002.

DILLINGER, Mike. O ensino gramatical: uma autópsia. In: SEMANA DE ESTUDOS DE LÍNGUA PORTUGUESA, I, 1993, Belo Horizonte. Departamento de Letras Vernáculas. Faculdade de Letras da UFMG, 1995, v.I, p. 31-65.

GNERRE, M. Linguagem, escrita e poder. São Paulo: Martins Fontes, 1985.

HAUY, Amini Boainain. Da necessidade de uma gramática-padrão da Lingua Portuguesa. 4.ed. São Paulo: Ática, 1994.

LEMLE, Miriam. O que a lingǘstica tem a dizer ao alfabetizador. In: Seminário Multidisciplinar de Alfabetização. Anais do Seminário Multidisciplinar de Alfabetização. Brasília: MEC/INEP, 1984, v. 1, p. 80-85

LIMA, Rosângela Borges. Estudo da norma escrita brasileira presente em textos jornalísticos e técnico-científicos. 2003. Tese (Doutorado em Estudos Lingüísticos) - Faculdade de Letras, UFMG, Belo Horizonte.

LUFT, Celso Pedro. Dicionário Luft. 2.ed. São Paulo: Ática, Scipione, 1991.

MARQUES, Rosilene Alessandra. Estudo gramatical e dominio da norma padrão: contradições no ensino de língua portuguesa e seus reflexos na produção de textos escritos. 2005. Dissertação (Mestrado em Estudos Lingüísticos) Faculdade de Letras, UFMG, Belo Horizonte.

MOURÃO, Eliane. Construções passivas do português: da regra à prescrição. In: Littera, Revista de Lingüística e Literatura. (Publ.: Curso de Letras da Faculdade de 
Ciências Humanas de Pedro Leopoldo). Minas Gerais, ano II, n. 3, jan./jun. 2001, p.54-67.

POSSENTI, Sírio. Por que (não) ensinar gramática na escola. São Paulo: Mercado de Letras, Associação de Leitura do Brasil, 1996.

RAMOS, Jânia M. O espaço da oralidade na sala de aula: texto e linguagem. São Paulo: Martins Fontes, 1997.

REVISTA Época, São Paulo, edições impressas de maio e junho de 2005.

RISSO, Mercedes Sanfelice. Língua falada - língua escrita: conceitos e preconceitos. In: [s.n.] Confluência: Boletim do Departamento de Lingüística. São Paulo: Faculdade de Ciências e Letras (Unesp), s.d., ano 3 (nº especial I EELA), p.55-63.

ROCHA, Luiz Carlos de Assis. Norma culta escrita: tentativa de caracterização. In: MENDES, Eliana Amarante de Mendonça, OLIVEIRA, Paulo Motta, BENNIBLER, Veronika (Org.) Revisitações: edição comemorativa - 30 anos da Faculdade de Letras da UFMG. Belo Horizonte: Faculdade de Letras da UFMG, 1999. p.119-142.

Gramática: nunca mais - o ensino da língua padrão sem o estudo da gramática. Belo Horizonte: Editora UFMG, 2002. 2002.

Como elaborar trabalhos acadêmicos. 3.ed. Belo Horizonte: Ed. do autor,

ROCHA LIMA, Carlos Henrique da. Gramática normativa da língua portuguesa. 43.ed. Rio de Janeiro: José Olympio, 2003.

SENA, Wagner da Rocha. Contribuição ao estudo da norma culta escrita do Português do Brasil. Rio de Janeiro: PUC, 1986 (Mestrado em Letras - Língua Portuguesa). 